\title{
The evolution and maintenance of gynodioecy in sexually and vegetatively reproducing plants
}

\author{
D. P. Stevens* $\ddagger$ and \\ J. M. M. Van Damme $\dagger$
}

\author{
* School of Biological Sciences, University College of \\ Swansea, Swansea, SA2 8PP, U.K. \\ $\dagger$ Department of Botanical Ecology, Institute for \\ Ecological Research, Weevers' Duin, Duinzoom 20a, \\ 3233 EG Oostvoorne, The Netherlands.
}

The evolution and maintenance of gynodioecy is explored theoretically at the ramet level in models that allow for differences between females and hermaphrodites in vegetative components of fitness as well as in sexual components.

For nuclear control of male sterility, it is shown that females may be maintained by selection in an otherwise hermaphrodite population through advantages over hermaphrodites in vegetative fitness components, even if there is no sex difference in maternal fitness components. The advantage required depends on the importance of vegetative reproduction. If females produce more daughter ramets than ovule offspring, the advantage in vegetative fitness components required to maintain females is numerically smaller than the well-known requirement of a two-fold advantage in maternal fitness components.

Three further findings in the nuclear models are that $(a)$ with some parameter combinations, females attain frequencies of higher than $\mathbf{0 \cdot 5}$, in which case their equilibrium frequency decreases rather than increases with increasing female advantage in seed fecundity; $(b)$ the advantage in adult survivability required to maintain a given equilibrium frequency of females becomes smaller with increasing reliance on vegetative reproduction; and (c) the rate of approach to equilibrium is inversely proportional to the level of vegetative reproduction in the population as a whole.

If male sterility is determined solely by cytoplasmic factors, females should be maintained if they have any advantage in vegetative reproduction over hermaphrodites, given that maternal fitness components are equal in the two sexes.

For nuclear-cytoplasmic control, it is shown that the premise that a joint polymorphism for cytoplasmic male sterility and nuclear fertility restoration should not be maintained in the absence of differences in fitness between sex genotypes of the same sex phenotype (Charlesworth and Ganders, 1979) may be generalised to situations where sex differences in vegetative reproduction occur.

The significance of vegetative reproduction in population genetic studies in general is briefly discussed.

\section{INTRODUCTION}

The conditions required for a female (male sterile) mutant to increase in frequency in an otherwise hermaphrodite population, and for the maintenance of a stable gynodioecious polymorphism, have been studied theoretically by several authors. These studies have shown that the conditions for polymorphism depend on the mode of inheritance of male sterility. With nuclear control of male sterility, females may be maintained in the population if they produce more than twice as many ovule offspring at reproductive maturity as hermaphro-

$\ddagger$ Present address: Wales Field Unit, Nature Conservancy Council, Plas Penrhos, Ffordd Penrhos, Bangor, Gwynedd, LL57 2LQ. dites produce (Lewis, 1941; Ross and Shaw, 1971; Lloyd, 1975; Charlesworth and Charlesworth, 1978); if their pre-adult survival rates are more than double, or their adult death rates less than half, those of hermaphrodites (Lloyd, 1974a; Van Damme and Van Damme, 1986); or if there is strong overdominance for fitness at the sex-determining loci or at closely linked loci (Ross and Weir, 1975; Gregorius, Ross and Gillet, 1982). With cytoplasmic control, females may be maintained if they have any advantage in ovule production, ovule offspring quality or survivability over hermaphrodites (Lewis, 1941; Lloyd, 1975). With nuclear-cytoplasmic control, which is being increasingly found in gynodioecious species (Ganders, 1978; Kheyr-Pour, 1980, 1981; Van Damme 
and Van Delden, 1982; Van Damme, 1983), the maintenance of a joint polymorphism for cytoplasmic male sterility and nuclear fertility restoration requires that the nuclear restorer allele reduces the fitness of its carriers (Charlesworth and Ganders, 1979; Charlesworth, 1981; Delannay, Gouyon and Valdeyron, 1981; Gouyon and Couvet, 1985); see Gouyon and Couvet (1985) and Ross and Gregorius (1985) for further models of nuclearcytoplasmic inheritance.

The unit of study in all models of gynodioecy to date has implicitly been the genet (genetic individual). However, models at the level of the ramet (physiological individual) may be of more general applicability. Ramet models enable vegetative components of fitness to be studied as well as sexual components. They reduce to give the same equilibrium equations as the corresponding genet models when there is no sex difference in vegetative reproduction, but even then vegetative reproduction per se has important consequences for gynodioecy, as discussed below.

In this paper, we explore the evolution and maintenance of gynodioecy in a population of sexually and vegetatively reproducing ramets for nuclear, cytoplasmic and nuclear-cytoplasmic control of male sterility. We use phenotypic and genetic models that are adaptations of the deterministic models developed by Lewis (1941), Lloyd (1975), Charlesworth and Charlesworth (1978), and Charlesworth and Ganders (1979), for genets. The models assume that there is no variation in fitness between sex genotypes of the same sex phenotype. The models for nuclear inheritance and cytoplasmic inheritance allow for overlapping generations and sex differences in adult survival rates in the manner of the model of Van Damme and Van Damme (1986). Phenotypic models for nuclear inheritance are applicable to a wide range of systems of disomic inheritance, including dominant and recessive male sterility and multifactorial control (Lloyd, 1977); situations in which these models are not appropriate are discussed by Lloyd (1977) and Van Damme and Van Damme (1986).

\section{THEORY}

\section{Basic parameters}

Let $p$ be the proportion of female ramets in a gynodioecious population. A proportion $S_{\mathrm{F}}$ of female ramets in this population survive to reproduce in the subsequent reproductive season compared with $S_{\mathrm{H}}$ of hermaphrodite ramets, the death rate of females relative to that of hermaphrodites being $D=\left(1-S_{\mathrm{F}}\right) /\left(1-S_{\mathrm{H}}\right)$. In any one reproductive season, female ramets produce $f$ times as many seeds as hermaphrodite ramets produce. The selfing rate of hermaphrodites is $s$, and the inbreeding depression (one minus the ratio of self to outcross offspring fitness) is $d$. For simplicity, inbreeding depression is assumed to affect only offspring quality and not seed quantity. Also in each season, hermaphrodites produce $v$ times as many daughter ramets as they potentially produce ovule offspring when none are lost through inbreeding depression ( $s=0$ and/or $d=0)$, and (unless $v=0$ ) females produce $r$ times as many daughter ramets as hermaphrodites produce. The ovule offspring and daughter ramets are counted at reproductive maturity, so the parameters $v$ and $r$ account for variation in the qualities of the vegetative propagules as well as in their quantities.

\section{Nuclear inheritance}

The fitnesses of hermaphrodite and female ramets are represented by their expectations of future genetic contributions to the next generation of ramets at reproductive maturity. Females contribute one genome to each of their ovule offspring, and two to each of their daughter ramets. Hermaphrodites, on the other hand, contribute two genomes to each of their self offspring, one to each of their outcross ovule offspring, one to each of the ovule offspring of both hermaphrodites and females that they father, and two to each of their daughter ramets. The relative genetic contributions in any one reproductive season are therefore $f+2 r v$ for females and $2 s(1-d)+2(1-s)+f p /(1-p)+$ $2 v$ for hermaphrodites. The expectations of future genetic contributions are then found by dividing these quantities by the appropriate sex specific death rates.

The population should reach a stable equilibrium, which is maintained by frequency-dependent selection (Ross and Shaw, 1971; Lloyd, $1974 b, 1975)$, when the average fitnesses of females and hermaphrodites are equal (Lloyd, 1977), i.e., when

$$
\frac{f+2 r v}{1-S_{\mathrm{F}}}=\frac{2(1-s d)+f p /(1-p)+2 v}{1-S_{\mathrm{H}}} .
$$

To find the equilibrium frequency of female ramets, we solve for $p$ and find

$$
p=\frac{f-2 D(1-s d)+2 v(r-D)}{f(1+D)-2 D(1-s d)+2 v(r-D)} .
$$


This equation generalises those of Lewis (1941), Lloyd (1975), Charlesworth and Charlesworth (1978), and Van Damme and Van Damme (1986), to situations in which vegetative as well as sexual reproduction occurs and the population frequencies of ramets rather than genets are considered. Three main points may be made about equation (2).

Consider first the maintenance of a gynodioecious polymorphism at the ramet level by sex differences in vegetative reproduction $(r)$. If females and hermaphrodites differ in only this respect $(f=D=1, s d=0)$, equation (2) reduces to $p=(2 v(r-1)-1) /(2 v(r-1))$. Plots of $p$ against $r$ for several values of $v$ are shown in fig. 1. Females should be maintained in the population if they are sufficiently superior to hermaphrodites in vegetative reproduction, the advantage required depending on the importance of vegetative reproduction. In fact, the inequality $r>1+1 / 2 v$ should be satisfied. With equal daughter ramet and ovule offspring production by hermaphrodites $(v=1)$, for example, females should be maintained if they produce more than 1.5 times as many daughter ramets as hermaphrodites produce. The curves in fig. 1 rise steeply, showing that considerable female frequencies can be maintained by relatively low fitness differences. For example, with $v=1$ again,

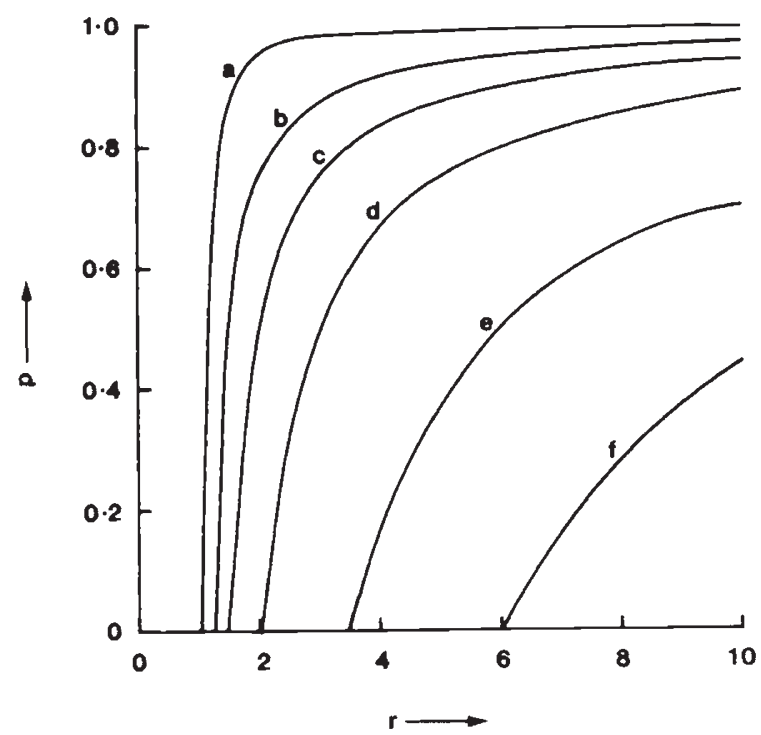

Figure 1 The relationship between the equilibrium frequency of female ramets $(p)$ and sex differences in daughter ramet production $(r)$ for various levels of vegetative reproduction $(v)$, assuming that the death rates of females and hermaphrodites are equal $(D=1)$ and that females and hermaphrodites produce equal numbers of ovule offspring at reproductive maturity $(f=1, s d=0)$. (a) $v=10 ;$ (b) $v=2$; (c) $v=1$; (d) $v=0.5$; (e) $v=0.2$; (f) $v=0.1$. females should attain a frequency of 0.5 with only a two-fold advantage. With higher values of $v$, more females are maintained by a given female advantage. It is also apparent from fig. 1 that female frequencies of greater than 0.5 are theoretically possible with female advantage in vegetative reproduction, as they are with female advantage in adult survivability (Van Damme and Van Damme, 1986).

Consider now the effect of vegetative reproduction per se, i.e., no sex difference $(r=1)$, on the maintenance of gynodioecy by female advantage in each of the two fitness characters studied by previous authors: ovule offspring production and adult survivability. To consider the former character alone, set $D=1$ (equal survivability), and find that $v$ drops out of equation (2), which therefore reduces to $p=(f-2(1-s d)) /(2 f-2(1-s d))$, the familiar equation of Lloyd (1975) and Charlesworth and Charlesworth (1978). Vegetative reproduction in itself therefore has no effect on the advantage in ovule offspring production required by females for their maintenance at a given equilibrium frequency. In contrast, the advantage in adult survivability required to maintain females is affected by the extent of vegetative reproduction. Setting $f=1$ and $s d=0$ (equal ovule offspring production), equation (2) now reduces to $p=$

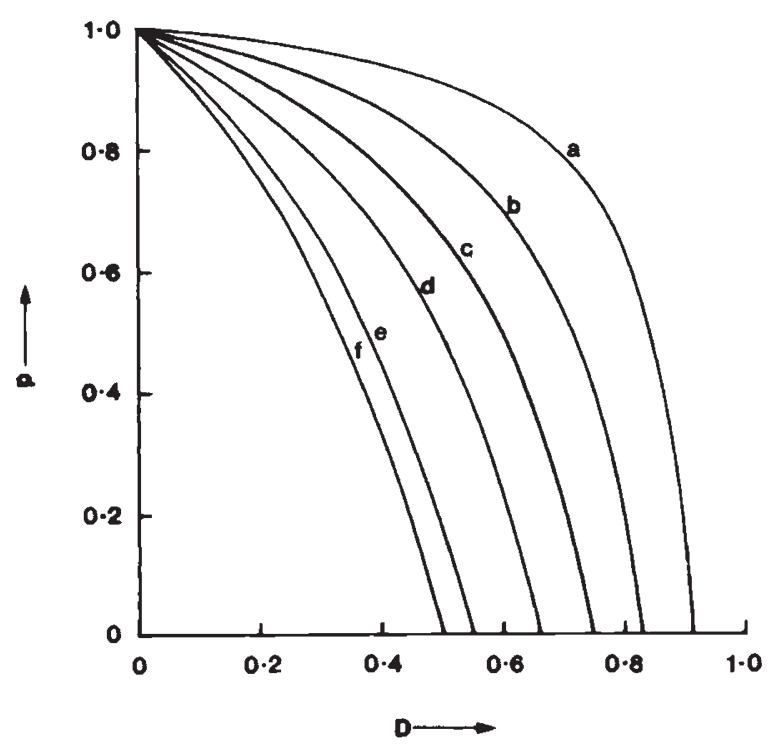

Figure 2 The relationship between the equilibrium frequency of female ramets $(p)$ and sex differences in adult survivability $(D)$ for various values of $v$, assuming that females and hermaphrodites produce equal numbers of ovule offspring and daughter ramets at reproductive maturity $(f=r=$ $1, s d=0)$. (a) $v=10$; (b) $v=2 ; \quad$ (c) $v=1$; (d) $v=0.5$; (e) $v=0.1$; (f) $v=0$ (the case of Van Damme and Van Damme, 1986). 
$(1-D(2+2 v)+2 v) /(1-D(1+2 v)+2 v) \quad$ (compare with equation (18.1) of Van Damme and Van Damme, 1986). Plots of $p$ against $D$ for several values of $v$ are shown in fig. 2 for this equation. It is clear that smaller sex differences in survivability are required to maintain a given equilibrium frequency of females as vegetative reproduction becomes increasingly important.

The third point to be made about equation (2) is that, with certain parameter combinations, the equilibrium frequency of female ramets may remain constant, or even decrease, with increasing female advantage in seed fecundity. This is shown in fig. 3 for the case when there are no sex differences in adult survivability $(D=1)$ or ovule offspring fitness $(s d=0)$. In this case, if the genetic contribution of females to the next generation through ramet production ( $2 r v$ ) equals the sum of the contributions of hermaphrodites through ovule offspring and ramet production $(2+2 v)$, then equation (1) reduces to $f=f p /(1-p)$, implying an equilibrium frequency of 0.5 regardless of the value of $f$. This is because, at the equilibrium frequency, females and hermaphrodites make equal genetic contributions through the ovule offspring of females. Moreover, if females contribute more through daughter ramets than this $(r v>1+v)$, the equilibrium frequency of females is always more than 0.5 , and it decreases with

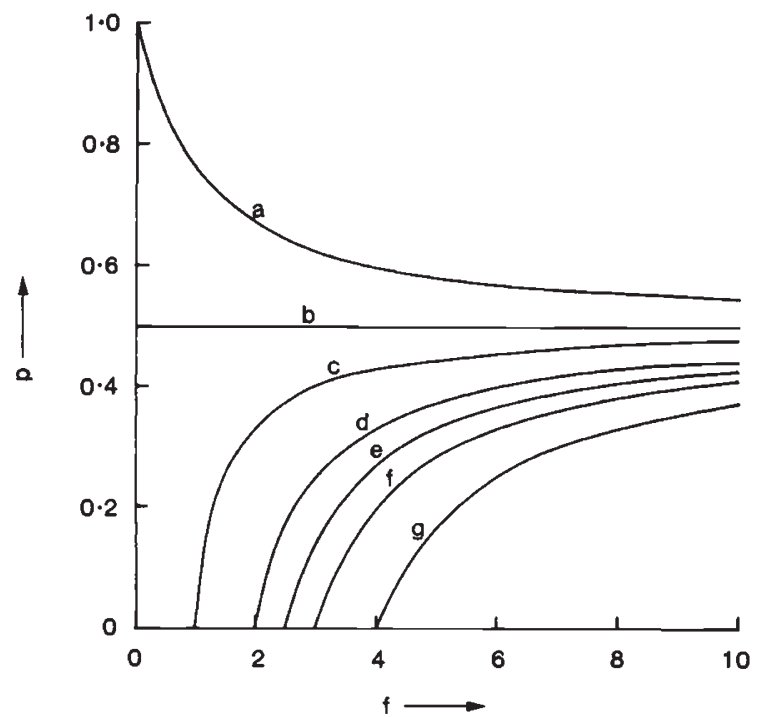

Figure 3 The relationship between the equilibrium frequency of female ramets $(p)$ and sex differences in seed fecundity $(f)$ for various values of $v$ and $r$, assuming that the death rates and ovule offspring fitnesses of females and hermaphrodites are equal $(D=1, s d=0)$. (a) $r=2, v=2$; (b) $r=$ $2, v=1$; (c) $r=2, v=0.5$; (d) $r=1, v=$ any (the case of Lewis, 1941); (e) $r=0.5, v=0.5$; (f) $r=0.5, v=1$; (g) $r=$ $0 \cdot 5, v=2$. increasing $f$, because hermaphrodites now make higher genetic contributions through the ovule offspring of females than do the females themselves. Only if the inequality $r v<1+v$ is satisfied is the situation reversed, $p$ now increasing with increasing $f$, as would normally be expected.

There appears to be no comparable situation in which the equilibrium frequency of females is independent of sex differences in adult survivability $(D)$, vegetative reproduction $(r)$, or ovule offspring fitness $(s d)$. However, independence of $p$ from $v$ occurs when $r=D$, i.e., when any advantage to females in vegetative reproduction $(r)$ is compensated for by a numerically equivalent advantage in survivability $(D)$ and vice versa; the special situation of $r=D=1$ has already been dealt with.

We now turn to the effect of vegetative reproduction on the rate of attainment of equilibrium, rather than on the equilibrium frequency of females itself. This was investigated in computer simulations of the number of generations for the frequency of females to rise from 0.01 to just below the equilibrium frequency $(p-0.001)$ using several combinations of $f, s, d$ and $v$. It was assumed that generations were non-overlapping $\left(S_{\mathrm{H}}=S_{\mathrm{F}}=0\right)$, that the two sexes produced equal numbers of daughter ramets $(r=1)$, that all parameters remained constant during a simulation (e.g., females fully fertilised so $f$ constant), and that sex expression was under single gene control with male sterility either completely dominant or recessive.

Some of the results are shown in table 1, where the number of generations taken to complete each simulation is compared with a mean index of vegetative reproduction in the population as a whole $\left(\bar{v}^{*}\right)$. This index was derived as follows. During the transition between any pair of generations, the relative importance of vegetative as opposed to sexual reproduction is given by the ratio of the number of daughter ramets to ovule offspring produced by the earlier generation, i.e.,

$$
v^{*}=\frac{v(r p+(1-p))}{f p+(1-p)(1-s d)},
$$

where $p$ is the female frequency in the earlier of the two generations. The mean index over the $N$ generations of a simulation as a whole $\left(\bar{v}^{*}\right)$ is also given by this equation, substituting $\bar{p}$, the mean female frequency in generations 0 to $N-1$, for $p$.

The main conclusion to be drawn from table 1 is that, for dominant and recessive male sterility separately, the rate of attainment of equilibrium is inversely proportional to the mean index of 


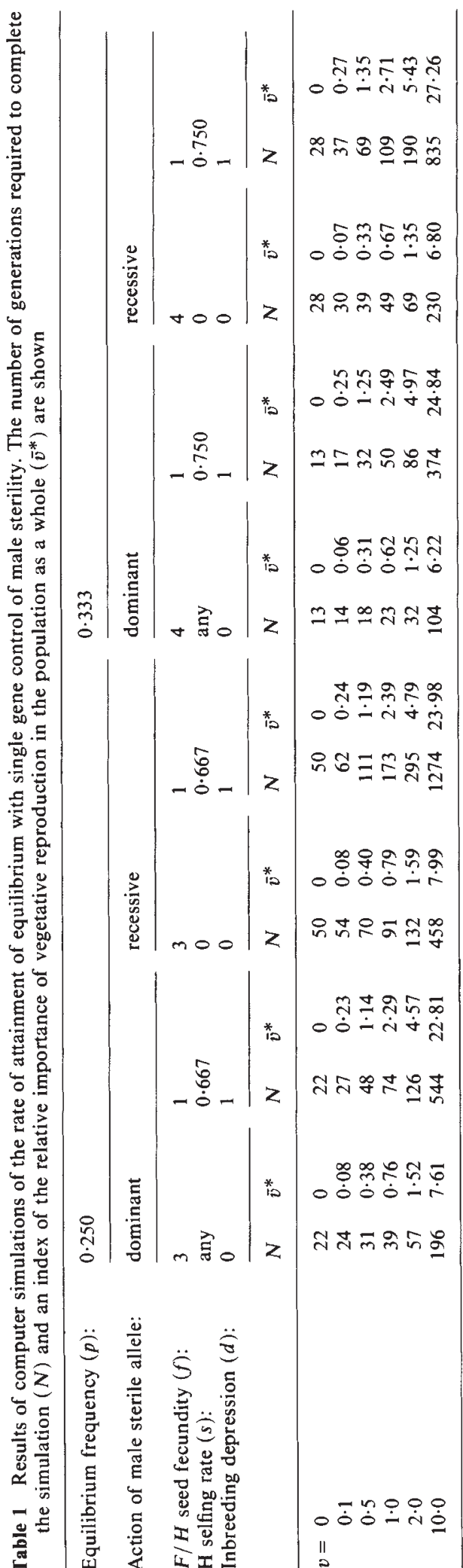

vegetative reproduction in the whole population $\left(\bar{v}^{*}\right)$. In other words, for each equilibrium frequency $\times$ mode of allelic action combination in table $1, N$ and $\bar{v}^{*}$ are perfectly correlated (apart from rounding errors). Changes in sex frequency are partially impeded by vegetative reproduction because the ramets in any particular generation that are derived vegetatively from the preceding generation have the same sex frequencies as the earlier generation. The situation is analagous to the well-known retarding effect of asexual reproduction on the approach to Hardy-Weinberg equilibrium (see Crow and Kimura, 1970, pp. 3839).

It is worth noting in passing that, in addition to vegetative reproduction, several other factors that leave the equilibrium frequency of females unaltered have an effect on the rate of attainment of equilibrium. For example, it is apparent from table 1 that equivalent simulations are completed much more quickly when male sterility is dominant than when it is recessive, and further simulations showed that, for recessive male sterility only, the selfing rate influences the number of generations required to reach equilibrium. Moreover, overlapping generations, without sex differences in survivability, should slow down the approach to equilibrium in a similar manner to vegetative reproduction, as is the case with the Hardy-Weinberg equilibrium (see Moran, 1962, pp. 23-24).

\section{Cytoplasmic inheritance}

The fitnesses of female and hermaphrodite ramets are now represented by their cytoplasmic contributions to the next generation of ramets at reproductive maturity. It is assumed that cytoplasmic factors are transmitted strictly maternally. The cytoplasmic contributions in any one reproductive season are $f+r v$ for females and $s(1-d)+1-s+v$ for hermaphrodites. Equating the expectations of future cytoplasmic contributions, the equilibrium equation becomes

$$
\frac{f+r v}{1-S_{\mathrm{F}}}=\frac{1-s d+v}{1-S_{\mathrm{H}}}
$$

which may be written as

$$
f+r v=D(1-s d+v) \text {. }
$$

We now wish to incorporate $p$ into equation (5), so that the effects of the fitness parameters on the equilibrium frequency of females may be analysed. The usual way of doing this is to partition the seed fecundity parameter $f$ into two components-ovule production $(o)$ and fertilisation 
rate $(e)$-each of which may be expressed as a female:hermaphrodite ratio, and then to specify a function of $p$ for $e$. Two frequency-dependent functions have been proposed for $e$, one by Lloyd $(1974 a, 1975)$ and the other by Charlesworth and Ganders (1979) and Charlesworth (1981). However, neither function allows for such fundamental complexities of pollination ecology as nonrandom pollinator movements and pollen carryover. More elaborate functions that overcome some of these restrictive assumptions can be formulated, but the equilibrium equations become complex and must be simplified by approximating procedures (D. P. Stevens, unpublished). For the present purposes, it is sufficient to note that, assuming $e$ is a negative function of $p$, and that $e$ tends to 1 as $p$ approaches 0 , females should be maintained in the population if

$$
o+r v>D(1-s d+v) .
$$

Females should therefore be maintained if they have any net advantage over hermaphrodites in ovule production, ovule offspring fitness, vegetative reproduction and survivability.

\section{Nuclear-cytoplasmic inheritance}

Gynodioecy with cytoplasmic control of male sterility may rapidly evolve to nuclear-cytoplasmic control through selection favouring nuclear fertility restoring mutations (Cosmides and Tooby, 1981). The type of nuclear-cytoplasmic inheritance in which cytoplasmic male sterility factors interact with nuclear restorer genes is therefore a particularly appropriate one for theoretical study. This form of inheritance was first modelled with sex differences in fitness parameters by Charlesworth and Ganders (1979), who showed that a joint polymorphism for cytoplasmic male sterility and nuclear fertility restoration should not be maintained under the assumption that genotypes of the same sex phenotype are equally fit.

Using Charlesworth and Ganders' equations, with additional terms to represent vegetative components of fitness, it is easy to show that their conclusion also applies to situations in which sex differences in vegetative reproduction occur. The reason for this is as follows.

Consider first the maintenance at equilibrium of the cytoplasmic polymorphism. This requires equal transmission of male fertile and male sterile cytoplasms between generations. Under the constraint of uniform fitness within each sex phenotype, equilibrium can only be maintained when the cytoplasmic contributions of the two sexes are equal, i.e., $f+r v=1-s d+v$ (the case of equation (5) when $D=1$ ).

Now consider the maintenance of the polymorphism at the nuclear restorer locus. With either recessive or dominant fertility restoration, the nonrestorer allele is at a selective disadvantage to the restorer allele, because the restorer is transmitted through both pollen and ovule whereas part of the paternal transmission of the non-restorer is cut off. A stable equilibrium requires that the two alleles have equal transmission rates. If hermaphrodites all have the same average fitness, the disadvantage to the non-restorer allele can only be balanced by a net female advantage in ovule offspring and ramet production, i.e., $f+r v>1-s d+v$ is necessary (albeit not sufficient).

The conditions required for the simultaneous maintenance of the cytoplasmic and nuclear polymorphisms are clearly contrary. Maintenance of the cytoplasmic polymorphism results in fixation of the nuclear restorer allele; maintenance of the nuclear polymorphism means fixation of the male sterile cytoplasm. We conclude that the occurrence of sex differences in vegetative reproduction in no way alters the conclusion of Charlesworth and Ganders (1979) as stated above. Only if the restorer allele reduces the fitness of its carriers can a joint polymorphism for cytoplasmic male-sterility and nuclear fertility restoration be maintained by selection, as discussed by Charlesworth (1981) and Gouyon and Couvet (1985).

\section{DISCUSSION}

\section{Vegetative reproduction and gynodioecy}

A partial reliance on vegetative reproduction is common in flowering plants in general (Abrahamson, 1980; Grant, 1981, p. 7; Silander, 1985; Richards, 1986, p. 371). For example, 46 per cent of 260 or so common and widespread species in the British flora have a strong capacity for vegetative spread (Salisbury, 1942, p. 215). Sexually dimorphic species are no exception. Indeed, Baker (1959) considered there to be an association between dioecy and self-incompatibility on the one hand and perenniality and vegetative reproduction on the other. Kay and Stevens (1986) discussed a number of dioecious and subdioecious species in the flora of the British Isles that rely heavily on vegetative reproduction, and several examples of vegetatively reproducing gynodioecious species are given in table 2 . 
Table 2 Some examples of gynodioecious species that reproduce vegetatively as well as sexually

\begin{tabular}{lll}
\hline & $\begin{array}{l}\text { Mode of vegetative } \\
\text { reproduction }\end{array}$ & Reference \\
\hline Cirsium acaule & rhizomes & Pigott (1968) \\
Euonymus europaeus & root buds & D. P. Stevens (personal observation) \\
Gingidia decipiens & not stated & Lloyd (1973) \\
Gingidia enysii & not stated & Lloyd (1973) \\
Gingidia montana & not stated & Lloyd (1973) \\
Glechoma hederacea & stolons & Slade and Hutchings (1987) \\
Iris douglasiana & rhizomes & Uno (1982a, b) \\
Lignocarpa carnulosa & not stated & Lloyd (1973) \\
Origanum vulgare & rhizomes & Lewis and Crowe (1956), Kheyr-Pour (1980) \\
Saxifraga granulata & bulbils & Stevens and Richards (1985) \\
Silene vulgaris & stolons & Dulberger and Horovitz (1984) \\
Succisa pratensis & lateral buds & Kay (1982) \\
\hline
\end{tabular}

Vegetative reproduction per se has several important consequences for gynodioecy. One consequence concerns the nature of fitness differences between hermaphrodites and females. It has been shown above that the more important vegetative reproduction is in a gynodioecious species, the smaller the advantage in both vegetative reproduction and adult survivability required for a nuclear male sterility allele to spread in the population; in contrast, there is no effect on the required level of seed production. The fate of the mutant allele will therefore depend on the way in which its pleiotropic effect compensates for the male sterility. For example, a compensatory increase in daughter ramet production should become more beneficial to females than a similar increase in ovule offspring production as vegetative reproduction becomes more important. Balanced against this advantage of vegetative reproduction, vegetative propagules may be more expensive in terms of energy and/or mineral nutrients to produce than seeds (e.g., Harmer and Lee, 1978), although developing ramets may contribute to their own cost by photosynthesis and/or mineral absorbtion in some species (Sarukhán, 1976; Abrahamson, 1980; Lee and Harmer, 1980).

A second consequence of vegetative reproduction concerns the dynamics of the evolutionary conflict between nuclear and cytoplasmic genes (Eberhard, 1980; Cosmides and Tooby, 1981; Gouyon and Couvet, 1985). It seems that as vegetative reproduction becomes increasingly prevalent at the expense of sexual reproduction, the transmission genetics of nuclear and cytoplasmic DNA becomes less disparate. In the extreme situation, where all reproduction is vegetative, both types of genetic material are transmitted in identical fashion, i.e., through daughter ramets, and the conflict disappears. The existence of the nuclear-cytoplasmic conflict clearly depends on the presence of sexual reproduction.

A third consequence of vegetative reproduction for gynodioecy concerns the spatial distribution of sex types in natural populations. We wish to point out that a gynodioecious species with strong vegetative reproduction may show the same spatial distribution of sex types as a species with limited seed dispersal but without vegetative reproduction. An example of the former occurs in Saxifraga granulata, an example of the latter in Plantago lanceolata; in both species, patches of female plants surrounded by hermaphrodites have been found (Stevens and Richards, 1985; Van Damme, 1986).

\section{Ramet models of gynodioecy}

For some gynodioecious species, the models presented in this paper are not really necessary. These include vegetatively reproducing species in which genets can be delimited by simple field observations, as well as species that have no means of vegetative spread. In many other vegetatively reproducing species, genets are much more cryptic than this and cannot be readily delimited; examples for sexually dimorphic species are given by Lewis and Crowe (1956), Lloyd and Myall (1976), Kheyr-Pour (1980), Uno (1982b) and Stevens (in press). In species such as these, special techniques may be used to recognise genets. For example, careful comparisons of several phenotypic characters simultaneously may be made after cultivating transplanted ramets in a relatively uniform environment (Harberd, 1962, 1967; Harberd and Owen, 1969; Smith, 1972; Dale and Elkington, 1984). Alternatively, genets may be identified by genetic markers, such as multiallelic self-incompatibility loci (Harberd, 
1961, 1963), enzyme loci (Wu, Bradshaw and Thurman, 1975; Gray, Parsell and Scott, 1979; Silander, 1979; Jeffries and Gottlieb, 1983), and, potentially, restriction fragment length polymorphisms (see Helentjaris et al., 1986). However, these methods are time-consuming and, in some cases, costly, and have been used with no gynodioecious species to date. The ramet models provided in this paper therefore remain valuable for empirical studies of gynodioecy in many vegetatively reproducing species.

The models in this paper demonstrate the conditions under which it is feasible for gynodioecy to evolve and be maintained in a population of sexually and vegetatively reproducing ramets; only empirical studies can show whether females and hermaphrodites actually differ in sexual and/or vegetative fitness components. Several authors have compared sexual fitness components in sex types from gynodioecious populations (Connor, 1965; Assouad et al., 1978; Philipp, 1980; Webb, 1981; Van Damme, 1984; Van Damme and Van Delden, 1984), and a few comparisons of vegetative fitness components have also been made (Lloyd, 1973; Webb and Lloyd, 1980; Stevens, in press). The three latter studies confirm that sex types in natural gynodioecious populations may indeed differ in vegetative reproduction.

\section{Vegetative reproduction and population genetics}

A final, broader issue concerns the significance of vegetative reproduction in population genetics in general. It appears that, despite its widespread occurrence, many of the population genetical consequencies of vegetative reproduction are only recently beginning to be seriously explored (e.g., Ellstrand and Roose, 1987; Gliddon, Belhassen and Gouyon, 1987). Possibly one reason for this is the insistence of the influential population ecologist Harper (1977, pp. 26-27) that the production of daughter ramets should always be regarded as a form of growth, never as a type of reproduction. We suggest that, for some purposes, it may be more informative to treat ramet production as a reproductive process. Only by doing this has the present paper enabled the genetical and evolutionary consequences of vegetative reproduction in gynodioecious species to be recognised.

Acknowledgements We are grateful to Drs Q. O. N. Kay, A. J. Richards and J. P. Stevens for their helpful comments on the manuscript.

\section{REFERENCES}

ABRAHAMSON, W. G. 1980. Demography and vegetative reproduction. In Solbrig, O. T. (ed.) Demography and Evolution in Plant Populations, Blackwell Scientific Publications, Oxford, pp. 89-106.

ASSOUAD, M. W., DOMMÉE, B., LUMARET, R. AND VALDEYRON, G. 1978. Reproductive capacities in the sexual forms of the gynodioecious species Thymus vulgaris L. Bot. J. Linn. Soc., 77, 29-39.

BAKER, H. G. 1959. Reproductive methods as factors in speciation in flowering plants, Cold Spring Harb. Symp. quant. Biol., 24, 177-191.

CHARLESWORTH, B. AND CHARLESWORTH, D. 1978. A model for the evolution of dioecy and gynodioecy. Am. Nat., 112, 975-997.

CHARLESWORTH, D. 1981. A further study of the problem of the maintenance of females in gynodioecious species. Heredity, 46, 27-39.

CHARLESWORTH, D. AND GANDERS, F. R. 1979. The population genetics of gynodioecy with cytoplasmic-genic malesterility. Heredity, 43, 213-218.

CONNOR, H. E. 1965. Breeding systems in New Zealand grasses. VI. Control of gynodioecism in Cortaderia richardii (Endl.) Zotov. N. Z. Jl Bot., 3, 233-242.

COSMIDES, L. M. AND TOOBY, J. 1981. Cytoplasmic inheritance and intragenomic conflict. J. Theor. Biol., 89, 83129.

CROW, J. F. AND kimura, M. 1970. AnIntroduction to Population Genetics Theory. Harper and Row, New York.

DALE, A. AND ELKINGTON, T. T. 1984. Distribution of clones of Galium boreale on Widdybank Fell, Teesdale. New Phytol., 96, 317-330.

DELANNAY, D., GOUYON, P. H. AND VALDEYRON, G. 1981. Mathematical study of the evolution of gynodioecy with cytoplasmic inheritance under the effect of a nuclear restorer gene. Genetics, 99, 169-181.

DUlberGer, R. AND HOROVITZ, A. 1984. Gender polymorphism in flowers of Silene vulgaris (Moench) Garcke (Caryophyllaceae). Bot. J. Linn. Soc., 89, 101-107.

EBERHARD, W. G. 1980. Evolutionary consequences of intracellular organelle competition. Q. Rev. Biol., 55, 231249.

Ellstrand, N. C. AND RoOse, M. L. 1987. Patterns of genotypic diversity in clonal plant species. Am. J. Bot., 74, 123-131.

GANDERS, F. R. 1978. The genetics and evolution of gynodioecy in Nemophila menziesii (Hydrophyllaceae). Can. J. Bot., 56, 1400-1408.

GLIDDON, C., BELHASSEN, E. AND GOUYON, P.-H. 1987. Genetic neighbourhoods in plants with diverse systems of mating and different patterns of growth. Heredity, 59, 2932.

GOUYON, P. H. AND COUVET, D. 1985. Selfish cytoplasm and adaptation, variations in the reproductive system of thyme. In Haeck, J. and Woldendorp, J. W. (eds) Structure and Functioning of Plant Populations. 2. Phenotypic and Genotypic Variation in Plant Populations, North-Holland Publishing Co., Amsterdam, pp. 299-319.

GRANT, v. 1981. Plant Speciation, Second edition. Columbia University Press, New York.

GRAY. A. J., PARSELL. R. J. AND SCOTT, R. 1979. The genetic structure of plant populations in relation to the development of salt marshes. In Jeffries R. L. and Davy, A. J. (eds) Ecological Processes in Coastal Environments, Blackwell Scientific Publications, Oxford, pp. 43-64. 
GREGORIUS, H.-R., ROSS, M. D. AND GILLET, E. 1982. Selection in plant populations of effectively infinite size. III. The maintenance of females among hermaphrodites for a biallelic model. Heredity, 48, 329-343.

HARBERD, D. J. 1961. Observations on population structure and longevity of Festuca rubra L. New Phytol., 60, 184-206.

HARBERD, D. J. 1962. Some observations on natural clones in Festuca ovina. New Phytol, 61, 85-100.

HARBERD, D. J. 1963. Observations on natural clones of Trifolium repens L. New Phytol., 62, 198-204.

HARBERD, D. J. 1967. Observations on natural clones in Holcus mollis. New Phytol., 66, 401-408.

HARBERD, D. J. AND OWEN, M. 1969. Some experimental observations on the clone structure of a natural population of Festuca rubra L. New Phytol., 68, 93-104.

HARMER, R. AND LEE, J. A. 1978. The growth and nutrient content of Festuca vivipara (L.) Sm. plantlets. New Phytol., 80, 99-106.

HARPER, J. L. 1977. Population Biology of Plants. Academic Press, London.

hElentJaris, T., SLOCUM, M., WRIGHT, S., SCHAEFER, A. AND NIENHUIS, J. 1986. Construction of genetic linkage maps in maize and tomato using restriction fragment length polymorphisms. Theor. Appl. Genet., 72, 761-769.

JEFFRIES, R. L. AND GOTTLIEB, L. D. 1983. Genetic variation within and between populations of the asexual plant Puccinellia $\times$ phryganodes. Can. J. Bot., 61, 774-779.

KAY, Q. O. N. 1982. Intraspecific discrimination by pollinators and its role in evolution. In Armstrong, J. A., Powell, J. M. and Richards, A. J. (eds) Pollination and Evolution, Royal Botanic Gardens, Sydney, pp. 9-28.

KAY, Q. O. N. AND STEVENS, D. P. 1986. The frequency, distribution and reproductive biology of dioecious species in the native flora of Britain and Ireland. Bot. J. Linn. Soc., 92, 39-64.

KHEYR-POUR, A. 1980. Nucleo-cytoplasmic polymorphism for male sterility in Origanum vulgare L. J. Hered., 71, 253-260.

KHEYR-POUR, A. 1981. Wide nucleo-cytoplasmic polymorphism for male sterility in Origanum vulgare L. J. Hered., 72, 45-51

LEE, J. A. AND HARMER, R. 1980. Vivipary, a reproductive strategy in response to environmental stress? Oikos, 35, 254-265.

LEWIS, D. 1941. Male sterility in natural populations of hermaphrodite plants. New Phytol., 40, 56-63

LEWIS, D. AND CROWE, L. K. 1956. The genetics and evolution of gynodioecy. Evolution, 10, 115-125.

LLOYD, D. G. 1973. Sex ratios in sexually dimorphic Umbelliferae. Heredity, 31, 239-249.

LLOYD, D. G. 1974a. Theoretical sex ratios of dioecious and gynodioecious angiosperms. Heredity, 32, 11-34.

LLOYD, D. G. $1974 b$. The genetic contributions of individual males and females in dioecious and gynodioecious angiosperms. Heredity, 32, 45-51.

LLOYD, D. G. 1975. The maintenance of gynodioecy and androdioecy in angiosperms. Genetica, 45, 325-339.

LLOYD, D. G. 1977. Genetic and phenotypic models of natural selection J. Theor. Biol, 69, 543-560.

LLOYD, D. G. AND MYALL, A. J. 1976. Sexual dimorphism in Cirsium arvense (L.) Scop. Ann. Bot., 40, 115-123.

MORAN, P. A. P. 1962. The Statistical Processes of Evolutionary Theory. Clarendon Press, Oxford.

PHILIPP, M. 1980. Reproductive biology of Stellaria longipes Goldie as revealed by a cultivation experiment. New Phytol., 85, 557-569.

PIGoTT, C. D. 1968. Cirsium acaulon (L.) Scop. (Biological Flora of the British Isles). J. Ecol., 56, 597-612.
RICHARDS, A. J. 1986. Plant Breeding Systems. George Allen and Unwin Ltd., London.

ROSS, M. D. AND GREGORIUS, H.-R. 1985. Selection with gene-cytoplasm interactions. II. Maintenance of gynodioecy. Genetics, 109, 427-439.

ROSS, M. D. AND SHAW, R. F. 1971. Maintenance of male sterility in plant populations. Heredity, 26, 1-8.

ROSS, M. D. AND WEIR, B. S. 1975. Maintenance of male sterility in plant populations. III. Mixed selfing and random mating. Heredity, 35, 21-29.

SALISBURY, E. J. 1942. The Reproductive Capacity of Plants. G. Bell \& Sons Ltd., London.

SARUKHÁN, J. 1976. On selective pressures and energy allocation in populations of Ranunculus repens L., $R$. bulbosus L. and R. acris L. Ann. Mo. bot. Gdn, 63, 290-308.

SILANDER, J. A. 1979. Microevolution and clone structure in Spartina patens. Science, 203, 658-660.

SILANDER, J. A. 1985. Microevolution in clonal plants. In Jackson, J. B. C., Buss, L. W. and Cook, R. E. (eds) Population Biology and Evolution of Clonal Organisms, Yale University Press, New Haven, pp. 107-152.

SLADE, A. J. AND HUTCHINGS, M. J. 1987. The effects of nutrient availability on foraging in the clonal herb Glechoma hederacea. J. Ecol., 75, 95-112.

SMITH, A. 1972. The pattern of distribution of Agrostis and Festuca plants of various genotypes in a sward. New Phytol., 71, 937-945.

STEVENS, D. P. On the gynodioecious polymorphism in Saxifraga granulata L. (Saxifragaceae). Biol. J. Linn. Soc. (in press).

STEVENS, D. P. AND RICHARDS, A. J. 1985. Gynodioecy in Saxifraga granulata L. (Saxifragaceae). Pl. Syst. Evol., 51, 43-54.

UNO, G. E. 1982a. Comparative reproductive biology of hermaphroditic and male-sterile Iris douglasiana Herb. (Iridaceae). Am. J. Bot., 69, 818-823.

UNO, G. E. $1982 b$. The influence of pollinators on the breeding system of Iris douglasiana. Am. Midl. Nat., 108, 149-158.

VAN DAMME, J. M. M. 1983. Gynodioecy in Plantago lanceolata L. II. Inheritance of three male sterility types. Heredity, $50,253-273$.

VAN DAMME, J. M. M. 1984. Gynodioecy in Plantago lanceolata L. III. Sexual reproduction and the maintenance of male steriles. Heredity, 52, 77-93.

VAN DAMME, J. M. M. 1986. Gynodioecy in Plantago lanceolata L. V. Frequencies and spatial distribution of nuclear and cytoplasmic genes. Heredity, 56, 355-364.

VAN DAMME, J. M. M. AND VAN DAMME, R. 1986. On the maintenance of gynodioecy, Lewis' result extended. $J$. theor. Biol., 121, 339-350.

VAN DAMME, J. M. M. AND VAN DELdEN, w. 1982. Gynodioecy in Plantago lanceolata L. I. Polymorphism for plasmon type. Heredity, 49, 303-318.

VAN DAMME, J. M. M. AND VAN DELDEN, w. 1984. Gynodioecy in Plantago lanceolata L. IV. Fitness components of sex types in different life cycle stages. Evolution, 38, $1326-1336$.

WEBB, C. J. 1981. Test of a model predicting equilibrium frequencies of females in populations of gynodioecious angiosperms. Heredity, 46, 397-405.

WEBB, C. J. AND LlOYD, D. G. 1980. Sex ratios in New Zealand apioid Umbelliferae. N. Z. Jl. Bot., 18, 121126.

WU, L., BRADSHAW, A. D. AND THURMAN, D. A. 1975. The potential for evolution of heavy metal tolerance in plants. III. The rapid evolution of copper tolerance in Agrostis stolonifera. Heredity, 34, 165-187. 